\title{
The marketplace of rationalizations
}

\author{
Daniel Williams (iD \\ Corpus Christi College, Trumpington Street, Cambridge CB21RH, UK \\ Email:dw473@cam.ac.uk
}

(Received 15 February 2021; revised 07 December 2021; accepted 11 December 2021; first published online 03 March 2022)

\begin{abstract}
Recent work in economics has rediscovered the importance of belief-based utility for understanding human behaviour. Belief 'choice' is subject to an important constraint, however: people can only bring themselves to believe things for which they can find rationalizations. When preferences for similar beliefs are widespread, this constraint generates rationalization markets, social structures in which agents compete to produce rationalizations in exchange for money and social rewards. I explore the nature of such markets, I draw on political media to illustrate their characteristics and behaviour, and I highlight their implications for understanding motivated cognition and misinformation.
\end{abstract}

Keywords: belief-based utility; motivated reasoning; misinformation; rationalization; political epistemology

\section{Introduction}

One of the major developments in the past half-century of economic research has been a growing focus on the production, acquisition, and distribution of information in markets and other social processes (Arrow 1963; Stiglitz 2002). For example, research has increasingly drawn attention to the fact that the perfect information assumed in classic demonstrations of market efficiency is not a useful idealization but is systematically mistaken. In the real world, information is scarce and unevenly distributed. The result of this recognition has been an explosion of work on how rational agents should decide what information to acquire and how to acquire it, the role of imperfections and asymmetries of information in generating market failures, and various signalling and screening mechanisms that can address such market failures (Akerlof 1978; Stigler 1961; Stiglitz 1975; Spence 1978; for a review, see Birchler and Bütler 1999).

Whereas much of this early research assumed that scarce and unevenly distributed information is nevertheless sought out and processed in optimally rational ways, this assumption has in turn been challenged by a large body of empirical research in recent decades. For example, one important challenge has come from the heuristics and biases tradition in behavioural economics and its extensive documentation of people's reliance on cost-efficient heuristics that

(C) The Author(s), 2022. Published by Cambridge University Press. This is an Open Access article, distributed under the terms of the Creative Commons Attribution licence (http://creativecommons.org/licenses/by/4.0/), which permits unrestricted re-use, distribution and reproduction, provided the original article is properly cited. 
systematically bias judgement and decision-making away from optimality. According to this influential body of work, human minds are not optimizing statistical inference mechanisms but flawed and constrained 'satisficers' dependent on fast and frugal - and thus frequently suboptimal - cognitive mechanisms (Simon 1955, 1956; Kahneman et al. 1982; Kahneman 2003; Masatlioglu et al. 2012).

Another less influential challenge has come from a growing interest in 'beliefbased utility', a recent name for an idea that was taken for granted by classical economists such as Smith and Mill: namely, that beliefs are not merely instruments by which we inform our decisions but are themselves important targets of our preferences (see Abelson 1986; Bénabou and Tirole 2016; Loewenstein and Molnar 2018; Williams 2020). Because people assign value to beliefs for reasons independent of their truth, they often end up with systematically inaccurate models of reality. Such misinformation thus arises not because people are the victims of bounded rationality but because ignorance and self-deception can and often do have greater subjective utility than an accurate understanding of the world.

Several theorists have recently explored the implications of belief-based utility for understanding a range of economic and social phenomena (see Loewenstein and Molnar 2018 for a review). In this article I build upon this work. Specifically, I explore the implications of two characteristics of belief-based utility: (i) that preferences for similar beliefs are often widely distributed in society, and (ii) that belief 'choice' is subject to a rationalization constraint, such that individuals can only bring themselves to believe things for which they can find appropriate rationalizations. I argue that these facts give rise to a spontaneous market for rationalizations, a social structure in which agents compete to produce justifications of widely desired beliefs in exchange for money and social rewards such as attention and status. After making the case for the existence of such markets, the article has two principal aims: to explore their characteristics and behaviour, and to illustrate their importance for understanding both motivated cognition and the nature and causes of misinformation.

The article is both verbal and speculative. That is, I avoid mathematical formalism, and I advance several ideas and claims for which more empirical research is required. My aim is to make the case that this research is worth pursuing in terms that are as accessible as possible. Rationalization markets have important implications for social epistemology, the philosophy of mind, and the psychological and social sciences, and yet - with some important exceptions (Kahan 2017; Mercier 2020) - they have received little attention in any of these fields. ${ }^{1} \mathrm{I}$ aim to rectify that.

\footnotetext{
${ }^{1}$ Although Kahan (2017) does not write of markets, the concept of rationalization markets complements his 'motivated-public model of misinformation', according to which 'opportunistic misinformers' respond to a 'demand for information' from a public motivated to hold identity-based beliefs. Mercier (2020: 206) writes explicitly of a 'market for justifications', and notes that 'such a market arises only when we anticipate that some decisions are likely to be perceived as problematic,' although he also recognizes the demand for justifications of political views and the role that this plays in driving political media (Mercier 2020: 199-215). There is also related research in the political economy of media on how consumer preferences for the confirmation of priors drives certain forms of media bias (Gentzkow et al. 2015; see section 5).
} 
I structure the article as follows. In section 2 I outline a widespread model of beliefs as instruments that function to provide accurate, decision-relevant information. In section $3 \mathrm{I}$ describe how the existence of belief-based utility undermines this model, and I clarify the kinds of preferences, strategies, and constraints that underlie belief 'choice'. In section 4 I explain how belief-based preferences generate a market for rationalizations, which I illustrate by appeal to political media. Section 5 then concludes with a summary and overview of three important areas for future research on this topic.

\section{An instrumentalist model of belief}

Much of microeconomics is founded upon rational choice theory, a framework for understanding rational behaviour in terms of an agent's expectations and preferences, theoretical posits that function as analogues of the beliefs and desires central to folk psychology. In the canonical expected utility framework, for example, expectations and preferences are formalized in terms of probability and utility functions that map states of affairs to their subjective probabilities and utilities. Rational agents then choose between alternative actions to maximize expected utility, calculated as the sum of the product of the utilities and probabilities assigned to the possible outcomes of such alternatives (von Neumann and Morgenstern 1944).

This model and the many criticisms of it as a basis for understanding human decision-making are familiar. What I want to draw attention to here is the picture of belief that typically accompanies such modelling: namely, that beliefs function to provide agents with accurate information concerning the state of the world and the expected outcomes of possible actions that they can exploit in guiding their decisions (see Stigler 1961). ${ }^{2}$ As Birchler and Bütler (1999: 31) put it, 'Knowledge or information has a value. By reducing uncertainty, it helps us to take the right action'. I will call this the instrumentalist model of belief because it assumes that the value of beliefs derives entirely from their role as instruments for informing decisions. There are three important implications of this model.

First, because human beings are not born omniscient, information - and so the beliefs that encode information - must be acquired. People must therefore make decisions about what information to acquire and from whom to acquire it. Given the instrumentalist model, rational agents should choose to acquire information only when its expected benefits in reducing uncertainty outweigh its costs of acquisition, which in turn implies that agents should never avoid free information (i.e. information for which there are no costs of acquisition) (Good 1967; Stigler 1961). ${ }^{3}$

Second, rational agents should process any information that they do acquire in epistemically rational ways and thus conform to formal rules of deductive and inductive inference. In much of microeconomics, for example, it is assumed that

\footnotetext{
${ }^{2}$ In line with standard practice in economics, I use the term 'belief to include probabilistic beliefs or credences.

${ }^{3}$ An anonymous reviewer helpfully points out that this assumption might break down if the information solely increases uncertainty and chaos.
} 
agents are Bayesian (Birchler and Bütler 1999). Even among those who seek to integrate recent lessons from behavioural economics, however, it is often assumed that information processing aims at accuracy and only falls short of optimal procedures for achieving this aim due to practical constraints (see Kahneman and Tversky 1972).

Third, accurate and decision-relevant information becomes an economic good, albeit an unconventional one. For example, its dissemination is subject to the risk of deception, it is typically non-rivalrous (i.e. consuming information does not exclude others from consuming it) and non-excludable (i.e. limitable to only paying consumers), and it is opaque in the technical sense that information is difficult to evaluate before it is consumed (Stiglitz 2002). Much of information economics explores such distinctive characteristics and their diverse implications. Nevertheless, underlying much of this work is the assumption that the value of information is dependent on its role in informing decisions, whether private firms can profit from producing it or not.

\section{Belief-based utility}

The instrumentalist model of belief is wrong. People are often motivated to form beliefs for reasons independent of their accuracy. For example, people typically want to believe that they are decent people in control of their lives with a promising future whose advantages were justly earned and whose misfortunes were the result of injustice or bad luck (see Bortolotti 2015 for a review). Similarly, people are often motivated to hold and affirm beliefs that elicit social rewards (Williams 2020). Such tendencies of belief formation are widely documented in psychology and were taken for granted by classical economists (see Loewenstein and Molnar 2018). In fact, Adam Smith ([1759] 2010: 447) called self-deceit 'the fatal weakness' of human nature. It is only in recent decades, however, that economists within the rational choice tradition have begun to systematically explore the human taste for unfounded beliefs and its implications for economic and social phenomena (see Bénabou and Tirole 2016; Loewenstein and Molnar 2018).

In this section I clarify which preferences underlie belief-based utility (S3.1), the constraints that underlie belief 'choice' (S3.2), and the individual strategies by which people acquire desired beliefs (S3.3).

\subsection{Preferences}

Beliefs have complex non-epistemic effects, that is, effects over and above their capacity to encode information about the state of the world (Williams 2020). For example, a person's beliefs influence how they feel, which choices they are likely to make, and how they are treated by other agents. Because the desirability of such effects does not reliably track the accuracy of the underlying beliefs, people often have preferences for inaccurate beliefs. Such preferences can be loosely taxonomized in terms of whether they derive from personal or social effects, although in real-world cases these kinds of preferences often co-occur, complement, and reinforce each other (see Williams 2021). 
Personal sources of belief-based utility are preferences for beliefs that arise for reasons independent of their effects on other agents. For example, sometimes people are biased towards unfounded beliefs for hedonic reasons. It is painful to reflect upon one's flaws, a distressing situation, or an unpromising future, so people often opt for wilful ignorance or unfounded optimism. In other cases, people gravitate towards beliefs because of an aversion to performing specific actions. For example, a drug addict might deny the existence of her drug problem because of a recognition that she would be motivated to implement the obvious solution to this problem if she became aware of it.

Social sources of belief-based utility are preferences for beliefs that arise because of the actual or anticipated effects of such beliefs on other people. Such 'socially adaptive beliefs' are usefully modelled in terms of signalling (Funkhouser 2017; Williams 2020). Abstractly, signals are behaviours or objects designed or selected to communicate information to be detected by other agents. Socially adaptive beliefs are beliefs that agents form to communicate information to other agents. This signalling can take at least two different forms, however: namely, cases in which agents form beliefs with the (unconscious) aim of transmitting the contents of these beliefs to other agents (transmission), and cases in which agents form beliefs with the (unconscious) aim of advertising or displaying certain traits that they possess (advertisement) (Funkhouser 2017). As an example of the former, Trivers (2011) hypothesizes that people are systematically biased towards self-serving beliefs because of the role that they play in persuading other agents of self-serving propositions. As an example of the latter, an increasingly influential hypothesis is that individuals are often biased towards group-specific beliefs because of the role that they play in signalling group membership and loyalty (see Kahan 2017; Williams 2020; Funkhouser 2020).

\subsection{Costs, benefits and the rationalization constraint}

The concept of belief-based utility is useful for drawing attention to the fact that people are often motivated to form beliefs because of their desirable non-epistemic effects, but it is somewhat misleading insofar as it suggests that agents directly choose beliefs in accordance with their expected utility. They do not. It is impossible to directly choose to form a belief through a conscious appreciation of non-epistemic reasons (Williams 1973). No amount of money could induce you to simply choose to believe that the moon is made of cheese or that $2+2=5$, for example.

Given that such direct belief choice is impossible, how do people satisfy their belief-based preferences? It is useful to approach this question from the perspective of benefits, costs, and in-built psychological constraints that determine when a sufficient ratio of benefits to costs will drive belief formation (see Williams 2020).

The benefits of forming unfounded beliefs track the relative desirability of the kinds of non-epistemic effects described above. The costs involve the costs that result from holding evidentially unsupported and so likely inaccurate beliefs that frustrate one's ability to navigate reality effectively. Further, one must compare these costs and benefits to those of other available strategies. In the case of 
socially adaptive beliefs, for example, this includes simply pretending to hold the relevant beliefs when interacting with others. Such pretence has one obvious advantage: it enables one to maintain an evidentially well-supported set of private beliefs. Nevertheless, in some contexts this benefit is insignificant because the beliefs concern phenomena that agents have little ability to influence anyway (Kahan 2017) or because the beliefs are largely compartmentalized in the believer's mental life (Mercier 2020). Further, hiding or lying about one's beliefs has costs. For example, it demands the psychological complexity and cognitive load involved in maintaining a gulf between one's private beliefs and public behaviour, and it risks the reputational damage that accompanies the discovery that one is deceiving others about one's beliefs (see Trivers 2011; Funkhouser 2017).

Such cost-benefit considerations are relevant to whether agents are likely to form unfounded beliefs. Nevertheless, as noted above, even an extreme ratio of benefits to costs is not sufficient for belief 'choice'. The explanation seems to be this: motivated cognition - that is, unconsciously conforming how one seeks out, interprets, and processes information to arrive at desired beliefs - is subject to a rationalization constraint, such that agents can only bring themselves to believe things for which they can find genuinely epistemic reasons (i.e. reasons that justify the truth of the relevant beliefs), even if - as is the case with motivated cognition such reasons constitute post hoc rationalizations (see Kunda 1990). ${ }^{4}$ Rationalization is often viewed as an activity that occurs when a person seeks an epistemic justification for a conclusion that they want to reach for non-epistemic reasons (Schwitzgebel and Ellis 2017). As I am using the term here, however, it is preferable to think of rationalizations as a particular kind of information: namely, information created or selected to provide epistemic support for beliefs that agents want to hold for non-epistemic reasons. This definition thus leaves open what form this information takes, how rationalizations are produced, and - crucially for the focus of this paper - who produces them.

\footnotetext{
${ }^{4}$ Reviewing the empirical research on motivated reasoning, Kunda (1990: 1 ) thus notes that ' $t$ ] here is considerable evidence that people are more likely to arrive at conclusions that they want to arrive at, but their ability to do so is constrained by their ability to construct seemingly reasonable justifications for these conclusions'. There are several converging lines of evidence for this view: for example, there is evidence that motivated cognition is always accompanied by an 'illusion of objectivity', which would be difficult to maintain in the complete absence of epistemic justifications; there is evidence that motivated reasoning is highly constrained by an individual's prior beliefs in experimental paradigms in which motivated reasoning is induced by manipulating the desirability of certain conclusions; there is evidence that 'positive illusions' (e.g. inflated assessments of one's socially desirable traits) are constrained by what individuals feel capable of justifying, such that they are significantly reduced for unambiguous traits with objective criteria for assessment; and finally, there is experimental evidence for an 'affective tipping point' at which individuals are forced to relinquish desired opinions once the evidence against them is overwhelming and they can no longer be justified (Redlawsk et al. 2010; for reviews, see Kunda 1990; Mercier and Sperber 2017: 244-245; Williams 2020). Crucially, however, the evidence that motivated cognition is constrained by epistemic rationalisations does not imply that it is constrained by objectively compelling epistemic justifications. Instead, as Mercier (2020: 208) points out, 'When a piece of information is seen as a justification, we can afford to evaluate it only superficially ... by virtue of being post hoc'. Moreover, an anonymous reviewer helpfully notes that some people seek out justifications of beliefs that they merely pretend to hold and are thus likely to be especially unscrupulous in evaluating such justifications. Given space constraints, I ignore this important point in this article, although it no doubt also plays a significant role in shaping political media.
} 
Before continuing, it is worth briefly considering why belief 'choice' is subject to a rationalization constraint. One possibility assumed in much of the philosophical literature is that belief formation is subject to a rationality constraint, perhaps because beliefs necessarily 'aim at the truth' (see Williams 1973). I am sceptical. As demonstrated by many examples of conspiracy theories, ideological convictions, and religious beliefs for which people nevertheless find rationalizations, the rationalization constraint is consistent with the emergence of beliefs that are radically misaligned with reality. Instead, I favour an explanation that appeals to features of human social life: the rationalization constraint ensures that agents are always capable of defending the truth of their beliefs in the context of social argument and justification (see Mercier and Sperber 2017; Mercier 2020: 206). This is merely a conjecture, however. What matters in what follows is that belief 'choice' is subject to a rationalization constraint - a claim widely accepted in psychology (see Kunda 1990; Loewenstein and Molnar 2018) - not why it is.

\subsection{Means of belief 'choice'}

If belief 'choice' is subject to a rationalization constraint, belief-based utility gives rise to a demand for rationalizations. There is a large body of psychological research on how such rationalizations are produced. Most of this research focuses on information-sampling and information-processing biases (for a review, see Bortolotti 2015; Funkhouser 2019; Kunda 1990; see section 5 below). Information-sampling biases arise when individuals strategically alter which information they seek out and ignore in the interests of finding rationalizations for desired beliefs or avoiding evidence in tension with such desired beliefs. Information-processing biases arise when individuals interpret and process information in biased ways, and they include strategic variations in the time spent reasoning and deliberating, asymmetries in the standards required for accepting and rejecting evidence, and selective trust and distrust assigned to testimony in accordance with its congruence with desired beliefs (see Kunda 1990; Kahan 2017).

All these biased strategies are crucial for understanding how individuals generate and protect desired beliefs. What I want to draw attention to here is an assumption underlying almost all the research on this topic, however: namely, that the production of epistemic support for desired beliefs falls on the relevant individuals who desire such beliefs. In many cases this is clearly true. If I desire to believe that I do not have a drug problem, the task of satisfying this desire will likely fall upon me. Crucially, however, it is not always true. In many cases, preferences for similar beliefs are widely distributed among the population. When preferences are widely shared in this way, the task of satisfying such preferences is rarely delegated entirely to the individuals in possession of them. Everybody consumes food but not everybody produces it. I will now argue that something similar applies to belief 'choice': when preferences for unfounded beliefs are widely distributed, the demand for rationalizations creates a market for rationalizations, an emergent social structure in which agents compete to 
produce rationalizations for what people want to believe in exchange for money and social rewards.

\section{The structure and dynamics of rationalization markets}

Rationalization markets are social structures that emerge to provide epistemic support for beliefs that people want to hold for non-epistemic reasons. To understand such markets, it is useful to decompose them into rationalization consumers (S4.1), rationalization producers (S4.2), the nature of rationalizations as an economic good (S4.3), the media of exchange used to buy rationalizations (S4.4), and the market price and self-adjusting price mechanism that rationalization markets generate (S4.5). I will illustrate these characteristics by appeal to contemporary political media, although it is important to stress that this article is both theoretical and exploratory (see section 5 below). The task of rigorously applying the framework developed here to real-world phenomena must await future research.

\subsection{Consumers}

Consumer demand for rationalizations arises primarily from widely shared preferences for unfounded beliefs. ${ }^{5}$ Although there are potentially many examples of such preferences, I will focus here on cases in which shared beliefbased preferences are driven by group attachments. ${ }^{6}$

Humans are a coalitional species inclined to form strong group attachments, to draw sharp ingroup-outgroup distinctions, to align their own interests with those of their group's interests, to signal and detect signals of group commitment, and to exhibit various forms of ingroup favouritism, including not just a greater preference for ingroup members but also greater trust in and empathy for them as well (see Tooby and Cosmides 2010; Boyer 2018). Although such groupish psychological tendencies can form surprisingly easily (Tajfel 1982), they typically manifest themselves in their most powerful forms when it comes to stable, longterm groups that people feel invested in, such as ethnic, national, religious, political, or cultural groups (see Boyer 2018). Although these groups obviously differ enormously in their specific characteristics - for example, their size, structure, purpose, cohesiveness, membership criteria, and so on - they are united in often functioning as general-purpose 'amplification coalitions'

\footnotetext{
${ }^{5} \mathrm{An}$ important exception to this concerns cases in which a single consumer or small number of consumers nevertheless wield substantial wealth, power, or status. For example, the substantial benefits that an authoritarian ruler can confer on others might generate powerful incentives for agents to devote their time and energy to satisfying their preferences, including belief-based preferences. Given space constraints, I ignore such cases in this paper.

${ }^{6}$ Beliefs with social utility provide the most obvious - and likely most consequential - cause of rationalization markets, but there also exist widely shared preferences for beliefs with purely personal utility that plausibly also drive rationalization markets. For example, the desire for uplifting and optimistic beliefs with hedonic value is likely widely shared across a variety of domains (health, financial investments, etc.) and thus incentivizes the production of evidence and arguments optimised for rationalizing such beliefs.
} 
(Tooby and Cosmides 2010), exploiting various forms of cooperation and coordination to amplify the ability of members to advance their interests by means of selective (i.e. within-group) mutual aid, social support, and opportunities for collective action (see Boyer 2018).

Understood in this way, group attachments of otherwise highly diverse forms nevertheless typically give rise to shared belief-based preferences of two important kinds. First, just as individuals are often biased towards self-serving beliefs, group attachments motivate group-serving beliefs that justify the interests and actions of the group in general (see Trivers 2011). Second, group attachments motivate beliefs that signal group identity and loyalty, such as defining group beliefs, pro-ingroup and anti-outgroup beliefs, beliefs that become contingently associated with group membership, and beliefs associated with strategic costs that only committed group members would be willing to pay, such as beliefs that result in selective reputational damage in the eyes of outgroup members (see Funkhouser 2020; Mercier 2020; Williams 2020).

Recent years have seen a growing recognition in political science of the importance of group attachments for understanding belief formation, where these identities include national, religious, and cultural identities, and especially in the context of modern democratic politics - party-based identities and their associated forms of ingroup loyalty (Huddy 2001). As Achen and Bartels (2017) put it in their review and defence of what they call the group theory of democracy',

In the political sphere, the most salient groups are parties, and the selfjustifications that sustain group life are primarily grounded in - and constructed to maintain - partisan loyalties. People tend to adopt beliefs, attitudes, and values that reinforce and rationalize their partisan loyalties. (Achen and Bartels 2017: 296)

Thus, politics provides a context in which widespread consumer demand for groupfavourable rationalizations is likely to be high, not least because group-justifying and ingroup-signalling beliefs constantly come under threat from the opposing beliefs and arguments of competing political coalitions (see S4.5 below). Crucially, however, consumer demand for rationalizations need not and will not be explicitly advertised. Those who engage in motivated cognition do not consciously interpret their behaviour in this way (Kunda 1990). Nevertheless, the demand will manifest itself in people's behaviour - in the fact that they seek out information of a kind that is useful for rationalizing preferred beliefs and are willing to exchange money and other goods in return for them.

There is an extensive empirical literature demonstrating this demand for partisan rationalizations, 'a robust conclusion ... [of which] is that consumers tend to choose media whose biases match their own preferences or prior beliefs' (Gentzkow et al. 2015: 633), with 'the tendency to select news based on anticipated agreement ... strengthened among more politically engaged partisans' (Iyengar and Hahn 2009: 19; see also Knobloch-Westerwick and Meng 2009; Stroud 2010). As Pew Research Center (2014) reports of US political media consumption, for example, 'When it comes to getting news about politics 
and government, liberals and conservatives inhabit different worlds', with 'little overlap in the news sources they turn to and trust'. Of course, selectively seeking out information from sources with which one agrees might also reflect a generic confirmation bias or even an epistemically rational allocation of trust to sources whose professed worldviews match one's priors (Gentzkow and Shapiro 2006). Nevertheless, there are several features of the consumption of partisan media that provide evidence for a specific demand for partisan identity-based rationalizations.

First, partisans do not merely selectively expose themselves to identity-congruent information but will pay to avoid exposure to information and arguments generated by the other side (Frimer et al. 2017), a phenomenon predicted by the existence of belief-based preferences but which is difficult to explain by appeal to truth seeking or a generic confirmation bias.

Second, the concept of belief-based utility draws attention to an important distinction between beliefs that people merely happen to hold, and are thus open to revising, and beliefs that people want to hold, which generate a demand for rationalizations. Importantly, there is considerable evidence that political partisans often lack strong or stable beliefs on substantive political issues, and thus quickly revise their attitudes in response to changing party cues or elite messaging (Achen and Bartels 2017). Thus, Republican voters largely accepted the profound ideological changes in the Republican Party's attitudes towards trade and foreign policy under Trump in recent years (Brennan 2021). By contrast, the constant thread in right-wing media coverage during this period is the provision of evidence and arguments for why the Democrats constitute a threat and the Republicans should win power, which suggests that the beliefs that partisans seek justifications for are not simply whatever beliefs they happen to hold - many of which appear to be lightly held and easily revised - but rather the kinds of beliefs that social identities generate preferences for, such as pro-ingroup beliefs, antioutgroup beliefs, and the belief that one's group deserves power and status (see Benkler et al. 2018; Mason 2018).

Finally, there is evidence demonstrating that partisans who endorse partyfavourable misinformation demonstrate no decline in party support upon accepting from fact-checkers that the information is incorrect (Nyhan et al. 2020), which suggests that such information is often used to rationalize predetermined conclusions rather than to inform beliefs and decision-making (see Mercier 2020: 205).

\subsection{Producers}

A widespread demand for rationalizations creates an opportunity to profit from producing and selling them. Rationalization producers are those who seize this opportunity and devote time, energy, and other resources to producing information useful for justifying beliefs that people want to hold for non-epistemic reasons. As with other cases, such attempts at satisfying consumer demand should be viewed through the lens of competition: from the perspective of consumers, it is beneficial to shop around for the highest quality rationalizations provided at the lowest price, which means that producers will be able to sell their rationalizations only if they produce and sell rationalizations with these characteristics. One 
should thus expect rationalization markets to involve the resource-efficient effects of competition, including the delegation of production to those for whom it is most profitable to produce, the consequent division and specialization of labour, and the selection for high-quality, low-cost goods.

As with rationalization consumers, rationalization producers will not explicitly describe the rationalizations that they sell as rationalizations. That is, because those who engage in motivated cognition strive to uphold a self-image as unbiased and objective (Williams 2021), rationalization producers will advertise themselves as providers of impartial and accurate information. What matters, however, is not how rationalization producers describe the good that they sell but rather why this good is demanded. It is demanded because it rationalizes what people want to believe for non-epistemic reasons, and thus producers will only be able to profit if they produce information with characteristics specialized for this end (see S4.6 below). Further, rationalization producers need not consciously interpret their behaviour in terms of the production of rationalizations. What matters from the perspective of understanding the relevant market dynamics is that information is produced to satisfy consumer demand for rationalizations. How the consumers and producers in this market consciously understand or describe their behaviour is irrelevant.

Once again, there is an extensive body of evidence demonstrating that media firms that produce news and political content often present information that is systematically biased towards justifying the beliefs and narratives of partisan audiences (Larcinese et al. 2011; Puglisi and Snyder 2011). Summarizing the empirical literature, Gentzkow et al. (2015: 624) thus note that '[d]ifferent media outlets indeed select, discuss, and present facts differently, and they do so in ways that tend to systematically favour one side of the political spectrum or the other'. As I return to below (S4.5), much of this bias appears to be driven by consumer demand, and the presentation of biased information is invariably accompanied by what Benkler et al. (2018: 42) call the 'performance of objectivity'. For example, despite significant evidence that Fox News is systematically biased in its presentation of news and content towards favouring the Republican Party (DellaVigna and Kaplan 2007; Iyengar and Hahn 2009; Martin and Yurukoglu 2017), it presents itself as a source of objective and impartial coverage of events, and its overwhelmingly Republican audience exhibit high levels of trust in its credibility as a source of reliable, bias-free information (Pew Research Center 2014; see Benkler et al. 2018). This is highly consistent with the framework developed here: information tailored towards the rationalization of partisan beliefs is nevertheless presented and consumed as if it constitutes objective and impartial information.

\subsection{Rationalization as an economic good}

Rationalizations take the form of information selected for its role in providing epistemic reasons for what people want to believe for non-epistemic reasons. Rationalizations can thus take many forms. Consider, for example, widely shared nationalistic preferences among a population to believe that their nation and its actions are good and just. Rationalizations could take the form of selective 
information of the nation's good actions, false or partial historical narratives, biased interpretations of global events, abstract social theories that vindicate the nation's interests in general, reasons to discount the testimony and arguments of those who criticize the nation, and so on. All that matters is that the relevant information can be used in rationalizing people's preferred beliefs.

This has an important implication: rationalizations need not and often will not take the form of misinformation. In fact, information that is clearly inaccurate - or, more specifically, that is known to be inaccurate by its consumers - is of no value in the context of motivated cognition because it cannot rationalize (i.e. justify the truth of) one's desired belief. Thus, misinformation when it is provided in the service of rationalization must be difficult to detect as misinformation, at least by those consuming it.

There is compelling evidence for this feature of rationalizations in the role of misinformation and fake news in right-wing media in the USA over the past decade. Empirical research has consistently demonstrated that 'the right-wing media ecosystem differs categorically from the rest of the media environment ... [in] how much more susceptible it has been to disinformation, lies, and half-truths' (Benkler et al. 2018: 13). For example, analysis shows that during the 2016 presidential election, 'Fake news was both widely shared and heavily tilted in favour of Donald Trump' (Allcott and Gentzkow 2017: 212). Crucially, however, this greater receptivity to misinformation has only been made possible by a co-occurring decline of trust among many Republicans in misinformation-correcting institutions such as fact-checking bodies, science, and universities, a distrust that has itself been partially fuelled and rationalized by the output of right-wing media (see Benkler et al. 2018; Marietta and Barker 2019). Thus, Benkler et al. (2018: 78) describe how extremely influential rightwing media figures and institutions such as Rush Limbaugh and Fox News not only bias the information that they produce towards the confirmation of rightwing narratives but also seek to actively discredit 'other media [and institutions] that contradict what they say as themselves biased and hence untrustworthy'. For example, much of Rush Limbaugh's (2013) coverage of political affairs sought to undermine what he called 'the Four Corners of Deceit', namely 'government, academia, science, and the media'. This dependence of consuming partisan misinformation on distrust in those who identify it as misinformation is highly congruent with the framework developed here.

As noted, however, misinformation is not necessary for rationalizations, and rationalization producers can produce exclusively accurate information if they are skilled at filtering, framing, and constructing this information in selective ways. Importantly, such biased presentation of evidence and arguments appears to be much more prominent in partisan media than outright lies or factual inaccuracies (see Gentzkow et al. 2015). As Sobbrio (2014: 294) notes, although 'journalists may create a bias in their news reports by reporting false information ... this represents the least common mechanism of media bias', which instead typically takes the form of 'selection, slanting[, and] decisions as to how much or how little prominence to give a particular news item'. Thus, Puglisi and Snyder (2011) demonstrate that newspapers tailored to Democratic audiences give significantly more coverage to scandals involving Republican 
politicians than newspapers tailored towards Republican audiences (and vice versa), and Larcinese et al. (2011) identify a similar phenomenon when it comes to newspaper coverage of the deficit under the presidents of political parties opposed by their audiences. Once again, this pattern - the predominant focus on accurate but biased presentation of information - is what one would expect if such information functions to provide genuinely epistemic justifications of different partisan beliefs.

Like any other good, rationalizations can and do vary in their quality. Analogously to quality differences between defence lawyers whose function is to selectively provide information conducive to the defendant's interests, rationalization providers vary in how creative and effective their rationalizations are. Further, differences in characteristics (e.g. intelligence, creativity, etc.) and resources (e.g. time, money, etc.) among agents will cause inevitable differences in how easily or cost-efficiently they can produce rationalizations. As noted above, it is generally those producers who can generate the highest-quality rationalizations for the lowest price that will be most successful in rationalization markets.

Nevertheless, rationalizations are unlike many other kinds of economic goods in multiple respects. Like other forms of information, rationalizations are generally non-rivalrous in the sense that consuming them does not prevent others from consuming them, and they are difficult to make excludable in the sense that their consumption can be restricted only to paying consumers. Thus, as with information more generally (Stiglitz 2002), rationalizations can qualify as a public good of a kind that is difficult to extract private profits from. Further, rationalizations are opaque in the technical sense that their quality is difficult to evaluate prior to consumption (Birchler and Bütler 1999).

These characteristics imply that rationalization markets do not lend themselves to perfect competition, which requires completely homogeneous products, perfect information (and thus transparency), and other unrealistic conditions (see Debreu 1959). In some cases, the result is that rationalization production is viewed as a public good and so either falls short of the socially preferred level of production or is delegated to the state and other nonprofit-seeking institutions, as with many nations throughout history and up to the present that selectively fund research conducive to upholding certain nationalistic or ideological convictions. Nevertheless, genuine markets for information goods are ubiquitous because private firms manage to develop ways to profit from its creation and distribution.

Although there are multiple ways that this is achieved, the most common way is through the development of a unique reputation and brand as a reliable information producer (Birchler and Bütler 1999; Coiera 2000). This enables consumers to evaluate the source of information rather than the information itself, which can be done based on past experience, reviews, and so on, and it means that rationalization producers can profit from strategies such as transforming rationalizations from a public good into a club good (e.g. via newspaper or website subscriptions), extracting profits indirectly by selling the attention of consumers to advertisers, and capitalizing on an important form of non-monetary exchange that I turn to in the next subsection. The result is 
typically monopolistic competition whereby large numbers of producers compete to sell differentiated products associated with distinctive brands (Varian 1999). This gives rationalization producers some short-term market power (i.e. an ability to exercise control over price), but entry costs are sufficiently low (anybody can start a blog or a YouTube channel, for example) and rationalization markets are sufficiently competitive that their long-run characteristics approximate the desirable effects of perfectly competitive markets (see Krugman and Wells 2008: Ch. 15) (see S4.5 below).

\subsection{Exchange}

Markets are typically understood in terms of monetary exchanges, and money often plays an important role when it comes to rationalization markets. Most obviously, individuals buy newspapers from or subscribe to firms that function to rationalize their shared political biases and convictions. Nevertheless, markets in general are not necessarily mediated by the exchange of money, and rationalization markets also involve the exchange of other goods.

In fact, one of the surprising things about information production in general is that so much of it occurs in the absence of any obvious financial incentive. For example, people devote significant time and energy to things such as YouTube videos, tweets and twitter threads, blogs, consumer reviews, and so on, often without receiving any financial compensation for doing so. On the face of it, this is puzzling. It is obvious why people can benefit from consuming such information, but why do people go to great lengths to produce it in the absence of clear financial rewards? A cost-benefit analysis would seem to imply a picture of human beings as information scroungers, eager to receive useful information but miserly in sharing it with others (see Acerbi 2019: 12). Such a picture is clearly wrong, however. Why?

One answer concerns attention. In building up a reputation as a reliable source of useful information of a particular kind, information producers will receive growing attention from those who desire this information. Attention likely has intrinsic value for at least some people, but it also provides an indirect means of extracting financial profits insofar as the attention of an information producer's audience can be sold to advertisers.

A second important answer concerns prestige, a distinctive kind of social status grounded in social admiration and deference and dependent on the public recognition that you possess characteristics and knowledge that enable you to help or confer benefits on others (Henrich and Gil-White 2001). Prestige is different from dominance, the other fundamental form of social status in human beings, insofar as it is dependent on the delivery of benefits rather than the imposition of costs, and it results in admiration, deference, and approach motivations rather than the fear and avoidance motivations associated with dominance hierarchies.

Prestige offers an important incentive for producing and sharing useful information. That is, the admiration and deference that ground prestige can be provided by consumers in exchange for access to and opportunities to learn from effective producers. This role of prestige in facilitating social learning underpins an influential theory of the evolution of prestige in the human 
lineage, according to which prestige status evolved at least in part so that individuals who benefit from the useful information produced by others can offer the benefits of increased status in return (Henrich and Gil-White 2001). Whatever the merits of this evolutionary proposal, prestige clearly plays a role in incentivizing the production of information today (Acerbi 2019). Acquiring a reputation as a producer of useful information is a means of acquiring admiration, deference, and gratitude from others. Social status thus provides a crucial medium of exchange in information markets generally and rationalization markets specifically.

These non-monetary forms of exchange are of course highly relevant to political media, especially in the digital age. That is, although certain firms are optimized for ordinary forms of financial profit maximization, a large amount of contemporary information in the political domain - including rationalizations - is produced by people seeking social rewards such as attention and prestige, which are in turn partially certified and quantified by metrics such as twitter followers, likes, retweets, YouTube subscribers, and so on.

There is a considerable body of evidence vindicating this perspective. ${ }^{7}$ In the context of political communication on social media, for example, 'Partisans selectively share fact-checking messages [on social media] that cheerlead their own candidate and denigrate the opposing party's candidate' (Shin and Thorson 2017: 233), posts on social media denigrating outgroup members provide some of the most viral content and are often generated by posters 'categorizing themselves by their political identities' (Rathje et al. 2021: 1), and partisan identity appears to constitute the primary motivation for sharing fake news on Twitter, most of which is tailored towards the confirmation of specific partisan beliefs and narratives (Osmundsen et al. 2021).

\subsection{The price of rationalizations}

Rationalization markets involve competition among producers to sell rationalizations for widely desired beliefs in exchange for money and other goods. As with all competitive markets of this kind, such exchanges are mediated by the price of rationalizations, a dynamic valuation influenced by the underlying forces of supply and demand. As we have seen, in rationalization markets this price can take the form of an explicit monetary value (e.g. the price of a book, newspaper subscription, etc.), but it might also take other less tangible forms (e.g. how much attention or admiration information producers receive for their product).

In perfectly competitive markets, all firms face a price for a good that is equal to marginal cost. As already noted, rationalization markets are not perfectly competitive in this sense. Rationalization producers have some market power, at least in the short run. A well-established newspaper optimized for rationalizing a particular set of political views will not go out of business immediately if it raises its subscription costs. Nevertheless, given the competitive nature of such markets and their low or non-existent entry costs, prices are still highly constrained by broader systemic forces of supply and demand. If The Guardian doubles its monthly subscription fee, I will change to the New York Times. If

\footnotetext{
${ }^{7}$ See Bail (2021) on the role of status seeking in driving partisan content on social media.
} 
you expect intense admiration for your amateurish partisan blog, you will be unlikely to find customers.

The overall demand for rationalizations is determined by factors such as how widespread and strong the preferences for specific beliefs are, as well as the wealth (both monetary and social) of those in possession of such preferences. Crucially, however, demand also continually fluctuates as desired beliefs come under epistemic 'threat' from various directions. Consider preferences for nationalistic beliefs within a country, for example. In many contexts, such desired beliefs will be continually challenged from various sources: for example, from new evidence of the nation's historical and current wrongdoing, from the novel arguments and interpretations of dissidents and critics, from the comparative success of other nations, and so on. When this happens, the demand for nationalist rationalizations that can neutralize such threats increases, which in turn pushes up the price of such rationalizations, thereby incentivizing existing producers to adapt their product and encouraging new producers to enter the market.

The supply of rationalizations is fundamentally determined by the scarcity of rationalizations and their production costs. As with information goods generally, it can be difficult to understand the concept of scarcity when it comes to rationalizations. As noted above, they are non-rivalrous. That is, any number of people can consume a single rationalization. This suggests that markets for rationalizations should be difficult to maintain. There are several reasons why this is mistaken. First, producing effective rationalizations for desired beliefs is non-trivial and often extremely difficult. Again, a useful analogy is with a defence lawyer tasked with justifying her client's innocence. Performing this task admits of significant variation in quality, and people will generally shop around for the best quality possible. Further, as with most information markets (see Birchler and Bütler 1999: 32), what people really shop around for is not rationalizations themselves but reputable sources of rationalizations: that is, firms that acquire reputations as reliable, low-cost producers of information that supports desired beliefs. Supply is thus highly constrained by the non-trivial ability of rationalization producers to develop such reputations.

As with competitive markets generally, variations in the price of rationalizations caused by variations in demand will be met by adjustments in supply. As price increases, it becomes profitable for more firms to attempt to enter the market or for existing firms to adapt their product; as price decreases, firms increasingly direct their efforts elsewhere or exit the market. The result of such fluctuating forces is a self-equilibrating price mechanism that aggregates dispersed information about belief-based preferences and ensures that time, energy, and talent are devoted to producing rationalizations in response to the target and intensity of such preferences.

At least at a coarse-grained level, one can see these dynamics clearly in the evolution of political media in the USA over the past 50 years. There is significant evidence that partisan sorting and political polarization have increased dramatically during this period, especially among the most politically engaged (see Benkler et al. 2018). Concretely, such polarization has involved a greater division of the American electorate into two contrasting political 
coalitions organized around distinct but correlated positions on a large range of issues, significantly increased levels of hostility towards partisans of opposing parties, and a dramatic reduction in the number of political independents. Although there is some controversy over the causes of this polarization, some factors are uncontroversial, including both an increased sorting of conservatives and liberals into the Republican and Democratic Party respectively after an unusual mid-20th century period in which these classifications often cross-cut each other, and the subsequent emergence of so-called 'mega-identities' as racial, religious, cultural, geographic, and even personality characteristics that were largely uncorrelated with party support in the mid-20th century have become increasingly correlated in recent decades (see Benkler et al. 2018; Mason 2018).

Importantly, this increase in political polarization has also coincided both with technological developments that have greatly increased the range of consumer choice, such as those involving satellite radio, cable television, and the internet, and the abandonment of federal legislation such as the Fairness Doctrine (repealed in 1987) that had curtailed the most highly partisan forms of news and political content (see Benkler et al. 2018 for a review).

Such dynamics have produced radical changes in the production and consumption of political media. In the middle decades of the 20th century, an electorate largely unpolarized along partisan lines consumed news and political content mostly from a handful of major news channels, which presented political information in a neutral, point-counterpoint format (Iyengar and Hahn 2009). By the second decade of the 21 st century, by contrast, an increasingly politically polarized electorate, greater consumer choice, and fewer restrictions on partisan media have conspired to produce two different media ecosystems catering to a politically divided electorate and presenting news and opinions in ways that are tailored towards the divergent preferences and worldviews of these distinct coalitions (see Pew Research Center 2014; Benkler et al. 2018).

These changes are highly consonant with the framework developed in this article. Increasing political polarization has increased the demand for partisan rationalizations, both because of the greater intensity of party identification and the greater number of partisans on each side, and technological changes and media deregulation have enabled the emergence of a media infrastructure optimized for the satisfaction of this increased demand. In this way, growing polarization produced 'a strong economic incentive for news organizations to cater to their viewers' political preferences' (Iyengar and Hahn 2009: 21), and 'ideologically specific media rose to meet the [growing] demand from the divided citizens those media serve (and from whom they profit)' (Marietta and Barker 2019: 14). For example, Fox News emerged in the 1990s with the strategy of catering to conservative audiences and quickly became the leading cable news provider, increasing its regular audience size by roughly 50\% between 2000 and 2004 while other cable providers showed no growth (Iyengar and Hahn 2009). In response, MSNBC changed its business strategy in 2006 away from centrist content to offering a consistently partisan perspective tailored towards the rationalization of liberal Democrat beliefs and narratives (see Martin and Yurukoglu 2017; Benkler et al. 2018). As polarization has continued to increase 
in recent years, political media has become increasingly partisan in response (Marietta and Barker 2019).

Of course, the causal relationship between political polarization and biased political media is likely bi-directional, with biased political media both catering to and fuelling partisan identities. Indeed, inflaming partisan identification and division can itself be viewed as a business strategy, insofar as it increases the demand for partisan media and their associated rationalizations (Mercier 2020: 241-246). Nevertheless, there are strong reasons to believe that the emergence of a highly partisan media ecosystem has in large part followed political polarization and the increased demand for partisan rationalizations that it generates. For example, purely 'supply-side' explanations of media bias that trace media bias to the preferences of company owners or manipulative elites struggle to explain the absence of significant partisan media bias in politically unpolarized countries, including in the USA when the population itself was unpolarized along partisan lines (see Iyengar and Hahn 2009; Boxell et al. 2020). Further, there is strong independent evidence that media bias is highly influenced by consumer demand (Gentzkow and Shapiro 2010; Larcinese et al. 2011; Puglisi and Snyder 2011; Durante and Knight 2012). Thus, analysis by Gentzkow and Shapiro (2010: 58) demonstrates that the partisan slant of newspapers is significantly positively correlated with the partisan preferences of their audiences and not their owners, such that after controlling for geographic factors and audience preferences there is 'no evidence that two jointly owned newspapers have a more similar slant than two randomly chosen newspapers'.

\subsection{Summary}

Rationalization markets emerge to satisfy a strange preference of Homo sapiens: to find epistemic reasons for beliefs held for non-epistemic reasons. In domains such as politics that involve intense intergroup competition, this demand for rationalizations adjusts in response to novel developments, new arguments, fresh critiques, and so on. Rather than striving to satisfy this demand themselves, most rationalization consumers implicitly delegate the task of production to a select subset of agents in exchange for money and social rewards, where such transactions are both mediated and incentivized by a self-adjusting price mechanism. The resultant competition selects for the emergence of firms that seek to build up reputations as reliable rationalization producers, resulting in a media landscape optimized for justifying identity-driven preferences for beliefs in cost-efficient ways.

As should be clear, rationalization markets are radically different to the information markets implied by the instrumentalist model of belief described in section 2, in which the demand for information derives from a desire for

\footnotetext{
${ }^{8}$ Of course, once a partisan media ecosystem is up and running, elites can no doubt influence the production of information in self-serving ways, but the point is that this is highly constrained by the identity-driven preferences of audiences (even if such preferences are themselves subject to elite-driven manipulation).
} 
accurate, decision-relevant beliefs. In such markets, information producers will be selected for the kinds of traits conducive to producing accurate information. As Tetlock and colleagues have demonstrated in an extensive body of empirical research going back decades, for example, accurate prediction 'demands thinking that is open-minded, careful, curious, and - above all - self-critical' (Tetlock and Gardner 2016: 20), and it requires characteristics such as integrative complexity (i.e. acknowledging uncertainty and integrating multiple perspectives), intellectual humility, and the willingness to treat beliefs as 'hypotheses to be tested, not treasures to be guarded' (Tetlock and Gardner 2016: 112; for empirical reviews, see Tetlock et al. 2014; Tetlock 2017). Insofar as information producers are selected for their ability to provide accurate information, one would expect the most successful of these producers to exhibit such epistemic virtues. In turn, one would expect the consumers of their information to become better informed because of such consumption, updating their beliefs in ways that reduce uncertainty and bring their model of reality more in line with the facts.

Things are completely different when it comes to rationalization markets. Because the function of firms in such markets is not to inform customers but to provide epistemic ammunition for predetermined conclusions, they will be selected for traits more characteristic of lawyers or press secretaries than dispassionate truth seekers, and their chief effects on consumers will be to sustain their confidence in beliefs that - given their basis in non-epistemic preferences - are likely to be inaccurate.

These features are especially clear when it comes to political media. For example, it is both obvious and empirically well-documented that political media frequently selects for epistemic vices in information producers and disseminators, including overconfidence and often outright certainty, an unwillingness to change one's mind or admit error, a stubborn inability to see things from multiple perspectives, and the strategic use of careful wordsmithing and obfuscation to insulate claims from empirical disconfirmation (see Tetlock 2017). The predictable result is that in many cases the success of pundits and opinion producers in the political domain when it comes to forecasting events - a useful metric for evaluating the degree to which their pronouncements and analyses approximate reality - is on average no better and in many cases worse than random (for reviews, see Tetlock et al. 2014; Tetlock 2017).

The effects of consuming such information are likewise predictable. Rather than bringing people's beliefs closer in line with reality, the result of more exposure to political information is often greater polarization and greater misinformation when it comes to factual issues of political significance. In a classic study, for example, Republicans in the USA were surveyed about their beliefs about the deficit during Bill Clinton's first term as president. Although it had more than halved, moderately well-informed Republicans were more misinformed on this topic than those least informed about politics (see Achen and Bartels 2017: 280-282). Similar findings apply when it comes to politically significant issues of societal risk such as global warming and genetically modified organisms: when facts are entangled with issues of identity and group-based loyalty, a greater exposure to political information often leads to greater polarization, not convergence (see Kahan 2017; Marietta and Barker 2019). 


\section{Future directions: modelling, motivated cognition, and social epistemology}

Rationalization markets are social structures in which agents compete to produce rationalizations for what people want to believe in exchange for money and social rewards, where such exchanges are both mediated and incentivized by a self-equilibrating price mechanism that flexibly adjusts the production of rationalizations to constantly evolving consumer demand. This article constitutes an initial, qualitative, and speculative attempt at describing and exploring the elements, structure, and behaviour of such markets, undertaken with the hope that it motivates others to develop this idea in the future. To that end, I will conclude by briefly highlighting three important areas for future research.

First, although the purely verbal and qualitative analysis undertaken here can be justified when first developing an idea and reviewing its diverse theoretical and empirical foundations, future research should strive to develop mathematical models of the structure and dynamics of rationalization markets.

The research literature that is most relevant to this aim is work in the microeconomics of media, which contains highly idealized models of the market forces that drive equilibrium media bias (Gentzkow et al. 2015). For example, Mullainathan and Shleifer (2005) present an influential model of news production in which consumers receive utility both from accurate news and news that is consistent with their priors and firms can decide to present news in ways that are 'slanted' towards the confirmation of different priors. To capture this situation, they adapt the classic Hotelling location model of product differentiation in which firms compete for customers whose locations represent preferences for products with variable characteristics and who therefore incur 'transportation costs' when purchasing from firms situated at different locations (see Tirole 1988: Ch. 7). In Mullainathan and Shleifer's (2005) model, consumers' preferred locations represent their priors on a one-dimensional political spectrum ranging from left to right, transportation costs are understood in terms of the disutility incurred from consuming news inconsistent with different priors, and firms locate themselves in product space by the degree to which their presentation of news is biased towards the confirmation of different priors.

Although this modelling framework and similar formal developments (Gentzkow et al. 2015) can illuminate certain stylized features of media bias, this body of research also exhibits several inadequacies when it comes to understanding political media. I will mention just two. First, this work typically rests on a simple model of confirmation bias in which individuals prefer information consistent with their priors in general (see Mullainathan and Shleifer 2005; Gentzkow et al. 2015). As noted above (S4.1), this perspective fails to track a crucial distinction between beliefs that individuals merely happen to hold - and are thus open to revising - and beliefs that constitute sources of utility and thus a demand for rationalizations. Second, such models fail to capture the dynamic element of the demand for rationalizations, including how this demand fluctuates in response to constantly evolving epistemic 'threats' in the context of intergroup competition (see S4.5). Once again, however, this 
dynamic element is crucial for understanding how partisan media not only responds to but also fuels the demand for partisan rationalizations.

Importantly, there is no reason why future modelling work could not accommodate these and other features of rationalization markets highlighted in this article. Thus, I hope that the more sophisticated framework for understanding the psychological, social, and epistemic features of belief-based utility and rationalizations can contribute to future developments in this area.

In addition to developing more formal and quantitative models, there are also several areas where rationalization markets have important implications for philosophy and the psychological and social sciences. I will mention two.

First, as noted above (S3.3), research in the philosophy of mind and psychology on motivated cognition and self-deception invariably assumes a highly individualistic understanding of such phenomena. Specifically, it assumes that individuals convince themselves of desired beliefs by in-the-head biases in information sampling and processing (e.g., Kunda 1990; Mele 2000). In sharp contrast to this dominant view, the concept of rationalization markets draws attention to an essentially social form of motivated cognition in which the task of protecting, reinforcing, and rationalizing desired beliefs is efficiently outsourced to the social environment. Just as one cannot understand how individuals in market economies acquire goods and services without understanding the broader social structure that makes such consumption possible, one cannot understand some of the most pervasive and consequential forms of motivated cognition without understanding how the production and consumption of epistemic support for desired beliefs is made possible by the systemic properties and incentives of the social world. This social and systemic perspective on motivated cognition warrants greater attention and exploration in philosophy and psychology.

Second, rationalization markets provide a unique, powerful, and yet largely unexploited lens for research in social epistemology and the social sciences into the production and distribution of misinformation. Although this taxonomy is somewhat artificial and by no means exhaustive, the dominant explanatory frameworks for understanding the generation and spread of misinformation can be divided into three groups: first, those that stress top-down disinformation attempts, including various subtle ways that propagandists can generate ignorance, confusion, and misperceptions by guiding particular forms of research production and manipulating informational networks (e.g. O'Connor and Weatherall 2019); second, those that stress the importance of individual psychological biases manifest in heuristic-based inference and motivated reasoning (e.g. Brennan 2016); and third, those that stress how tendencies of social affiliation interact with characteristics of informational networks such as social media to give rise to knowledge-obstructing phenomena such as echo chambers, false consensus, bootstrapped corroboration, and group polarization (e.g. Sunstein 2017).

Rationalization markets provide a framework for understanding the production and spread of misinformation that is distinct from such approaches and yet can integrate insights from all of them. Most obviously, this framework suggests a 
fundamentally bottom-up driver of misinformation in the individual psychology of belief-based utility and the demand for rationalizations, but it explains the production of information that sustains ignorance and inaccurate beliefs not primarily in terms of individualistic cognitive biases but by reference to broader, systemic social dynamics that adjust to these features of human psychology. Further, it suggests a novel lens on how to understand the kinds of information production that frequently facilitate ignorance and inaccurate beliefs. As we have seen, rationalizations rarely take the form of outright falsehoods or 'fake news'. Instead, they are optimized for providing epistemic justifications of predetermined conclusions. It is only because of the biased way that such reasons are selected and produced that their cumulative effect on individuals is often to entrench them in unfounded beliefs.

For these reasons and more, rationalization markets provide an important area for exploration in the large and growing body of research on the psychological and social drivers of societal ignorance and misinformation.

Acknowledgements. This research was generously supported by an Early Career Research Fellowship from Corpus Christi College, University of Cambridge. I would like to thank Lewis Gudgeon, Stephen Gadsby, two anonymous reviewers, and the editor of this journal for extremely helpful comments and feedback that greatly improved the article.

\section{References}

Abelson R. 1986. Beliefs are like possessions. Journal for the Theory of Social Behaviour 16, 223-250.

Acerbi A. 2019. Cultural Evolution in the Digital Age. Oxford: Oxford University Press.

Achen C.H. and L.M. Bartels 2017. Democracy for Realists: Why Elections do not Produce Responsive Government. Princeton, NJ: Princeton University Press.

Akerlof G.A. 1978. The market for "lemons": quality uncertainty and the market mechanism. In Uncertainty in Economics, 235-251. London: Academic Press.

Allcott H. and M. Gentzkow 2017. Social media and fake news in the 2016 election. Journal of Economic Perspectives 31, 211-236.

Arrow K.J. 1963. Uncertainty and the welfare economics of medical care. American Economic Review 53, 941-973.

Bail C. 2021. Breaking the Social Media Prism. Princeton, NJ: Princeton University Press.

Bénabou R. and J. Tirole 2016. Mindful economics: the production, consumption, and value of beliefs. Journal of Economic Perspectives 30, 141-164.

Benkler Y., R. Faris and H. Roberts 2018. Network Propaganda: Manipulation, Disinformation, and Radicalization in American Politics. Oxford: Oxford University Press.

Birchler U. and M. Bütler 1999. Information Economics. London: Routledge.

Bortolotti L. 2015. Irrationality. Cambridge: Polity Press.

Boxell L., M. Gentzkow and J.M. Shapiro 2020. Cross-country Trends in Affective Polarization. No. w26669. Cambridge, MA: National Bureau of Economic Research.

Boyer P. 2018. Minds Make Societies: How Cognition Explains the World Humans Create. New Haven, CT: Yale University Press.

Brennan J. 2016. Against Democracy. Princeton, NJ: Princeton University Press.

Brennan J. 2021. Does public reason liberalism rest on a mistake? Democracy's doxastic and epistemic problems. In Political Epistemology, eds E. Edenberg and M. Hannon, 135-155. Oxford: Oxford University Press.

Coiera E. 2000. Information economics and the internet. Journal of the American Medical Informatics Association 7, 215-221. 
Debreu G. 1959. Theory of Value: An Axiomatic Analysis of Economic Equilibrium. New Haven, CT: Yale University Press.

DellaVigna S. and E. Kaplan 2007. The Fox News effect: media bias and voting. Quarterly Journal of Economics 122, 1187-1234.

Durante R. and B. Knight 2012. Partisan control, media bias, and viewer responses: evidence from Berlusconi's Italy. Journal of the European Economic Association 10, 451-481.

Frimer J.A., L.J. Skitka and M. Motyl 2017. Liberals and conservatives are similarly motivated to avoid exposure to one another's opinions. Journal of Experimental Social Psychology 72, 1-12.

Funkhouser E. 2017. Beliefs as signals: a new function for belief. Philosophical Psychology 30, 809-831.

Funkhouser E. 2019. Self-deception. London: Routledge.

Funkhouser E. 2020. A tribal mind: beliefs that signal group identity or commitment. Mind and Language. https://doi.org/10.1111/mila.12326.

Gentzkow M. and J.M. Shapiro 2006. Media bias and reputation. Journal of Political Economy 114, 280-316.

Gentzkow M. and J.M. Shapiro 2010. What drives media slant? Evidence from US daily newspapers. Econometrica 78, 35-71.

Gentzkow M., J.M. Shapiro and D.F. Stone 2015. Media bias in the marketplace: theory. In Handbook of Media Economics, Vol. 1, 623-45. New York, NY: North-Holland.

Good I.J. 1967. On the principle of total evidence. British Journal for the Philosophy of Science 17, 319-321.

Henrich J. and F.J. Gil-White 2001. The evolution of prestige: freely conferred deference as a mechanism for enhancing the benefits of cultural transmission. Evolution and Human Behavior 22, 165-196.

Huddy L. 2001. From social to political identity: a critical examination of social identity theory. Political Psychology 22, 127-156.

Iyengar S. and K.S. Hahn 2009. Red media, blue media: evidence of ideological selectivity in media use. Journal of Communication 59, 19-39.

Kahan D. 2017. Misconceptions, misinformation, and the logic of identity-protective cognition. SSRN Electronic Journal. https://doi.org/10.2139/ssrn.2973067.

Kahneman D. 2003. Maps of bounded rationality: psychology for behavioral economics. American Economic Review 93, 1449-1475.

Kahneman D. and A. Tversky 1972. Subjective probability: a judgment of representativeness. Cognitive Psychology 3, 430-454.

Kahneman D., S.P. Slovic, P. Slovic and A. Tversky (Eds) 1982. Judgment under Uncertainty: Heuristics and Biases. Cambridge: Cambridge University Press.

Knobloch-Westerwick S. and J. Meng 2009. Looking the other way: selective exposure to attitude-consistent and counterattitudinal political information. Communication Research 36, 426-448.

Krugman P. and R. Wells 2008. Microeconomics. London: Macmillan.

Kunda Z. 1990. The case for motivated reasoning. Psychological Bulletin 108, 480-498.

Larcinese V., R. Puglisi and J.M. Snyder Jr 2011. Partisan bias in economic news: evidence on the agenda-setting behavior of US newspapers. Journal of public Economics 95, 1178-1189.

Limbaugh R. 2013. The Four Corners of Deceit: Prominent Liberal Social Psychologist Made It All Up. Transcript of syndicated radio broadcast of 29 April 2013. Accessed via RushLimbaugh.com.

Loewenstein G. and A. Molnar 2018. The renaissance of belief-based utility in economics. Nature Human Behaviour 2, 166-167.

Marietta M. and D.C. Barker 2019. One Nation, Two Realities: Dueling Facts in American Democracy. Oxford: Oxford University Press.

Martin G.J. and A. Yurukoglu 2017. Bias in cable news: persuasion and polarization. American Economic Review 107, 2565-2599.

Masatlioglu Y., D. Nakajima and E.Y. Ozbay 2012. Revealed attention. American Economic Review 102, 2183-2205.

Mason L. 2018. Uncivil Agreement: How Politics Became our Identity. Chicago, IL: University of Chicago Press.

Mele A.R. 2000. Self-deception Unmasked. Princeton, NJ: Princeton University Press.

Mercier H. 2020. Not Born Yesterday. Princeton, NJ: Princeton University Press. 
Mercier H. and D. Sperber 2017. The Enigma of Reason. Cambridge, MA: Harvard University Press.

Mullainathan S. and A. Shleifer 2005. The market for news. American Economic Review 95, 1031-1053.

Nyhan, B., E. Porter, J. Reifler and T.J. Wood 2020. Taking fact-checks literally but not seriously? The effects of journalistic fact-checking on factual beliefs and candidate favorability. Political Behavior 42, 939-960.

O’Connor C. and J.O. Weatherall 2019. The Misinformation Age: How False Beliefs Spread. New Haven, CT: Yale University Press.

Osmundsen M., A. Bor, P.B. Vahlstrup, A. Bechmann and M.B. Petersen 2021. Partisan polarization is the primary psychological motivation behind political fake news sharing on Twitter. American Political Science Review. https://doi.org/10.1017/S0003055421000290.

Pew Research Center 2014. Political Polarization and Media Habits. https://www.pewresearch.org/ journalism/2014/10/21/political-polarization-media-habits/.

Puglisi R. and J.M. Snyder Jr 2011. Newspaper coverage of political scandals. Journal of Politics 73, 931-950.

Rathje S., Van Bavel J.J. and S. van der Linden 2021. Out-group animosity drives engagement on social media. Proceedings of the National Academy of Sciences USA 118. https://doi.org/10.1073/pnas. 2024292118.

Redlawsk, D.P., A.J. Civettini and K.M. Emmerson 2010. The affective tipping point: do motivated reasoners ever "get it"? Political Psychology 31, 563-593.

Schwitzgebel E. and J. Ellis 2017. Rationalization in moral and philosophical thought. In Moral Inferences, eds. J.-F. Bonnefon and B. Trémolière, pp. 170-190. London: Routledge.

Shin J. and K. Thorson 2017. Partisan selective sharing: the biased diffusion of fact-checking messages on social media. Journal of Communication 67, 233-255.

Simon H.A. 1955. A behavioral model of rational choice. Quarterly Journal of Economics 69, 99-118.

Simon H.A. 1956. Rational choice and the structure of the environment. Psychological Review 63, 129.

Smith A. [1759] 2010. The Theory of Moral Sentiments. London: Penguin.

Sobbrio F. 2014. The political economy of news media: theory, evidence and open issues. In A Handbook of Alternative Theories of Public Economics, eds F. Forte, R. Mudambi and P.M. Navarra, 278-322. Cheltenham: Edward Elgar Publishing.

Spence M. 1978. Job market signaling. In Uncertainty in Economics, 281-306. London: Academic Press.

Stigler G.J. 1961. The economics of information. Journal of Political Economy 69, 213-225.

Stiglitz J.E. 1975. The theory of "screening," education, and the distribution of income. American Economic Review 65, 283-300.

Stiglitz J.E. 2002. Information and the change in the paradigm in economics. American Economic Review 92, 460-501.

Stroud N.J. 2010. Polarization and partisan selective exposure. Journal of Communication 60, 556-576.

Sunstein C.R. 2017. \# Republic. Princeton, NJ: Princeton University Press.

Tajfel H. 1982. Social Identity and Intergroup Relations. New York, NY: Henry Holt.

Tetlock P.E. 2017. Expert Political Judgment: How Good Is It? How Can We Know? New edn. Princeton, NJ: Princeton University Press.

Tetlock P.E. and D. Gardner 2016. Superforecasting: The Art and Science of Prediction. London: Random House.

Tetlock P.E., B.A. Mellers, N. Rohrbaugh and E. Chen 2014. Forecasting tournaments: tools for increasing transparency and improving the quality of debate. Current Directions in Psychological Science 23, 290-295.

Tirole J. 1988. The Theory of Industrial Organization. Cambridge, MA: MIT Press.

Tooby J. and L. Cosmides 2010. Groups in mind: the coalitional roots of war and morality. In Human Morality and Sociality: Evolutionary and Comparative Perspectives, ed. H. Høgh-Olesen, 91-234. London: Palgrave-Macmillan.

Trivers R. 2011. The Folly of Fools. London: Basic Books.

Varian H.R. 1999. Markets for Information Goods. Vol. 99. Institute for Monetary and Economic Studies, Bank of Japan.

von Neumann J. and O. Morgenstern 1944. Theory of Games and Economic Behavior. Princeton, NJ: Princeton University Press. 
Williams B. 1973. Deciding to believe. In Problems of the Self. Cambridge: Cambridge University Press. Williams D. 2020. Socially adaptive belief. Mind \& Language. https://doi.org/10.1111/mila.12294.

Williams D. 2021. Motivated ignorance, rationality, and democratic politics. Synthese 198, 7807-7827.

Daniel Williams is an Early Career Research Fellow at Corpus Christi College, University of Cambridge, and an Associate Fellow at the Leverhulme Centre for the Future of Intelligence, University of Cambridge. His current research explores the nature, causes and implications of motivated reasoning. URL: https://danwilliamsphilosophy.com.

Cite this article: Williams D (2023). The marketplace of rationalizations. Economics \& Philosophy 39, 99-123. https://doi.org/10.1017/S0266267121000389 